\title{
APROXIMACIÓN A LA ATENCIÓN HOSPITALARIA \\ EN LA ORDEN DE SAN JUAN: \\ LA COFRADÍA DE CONSUEGRA
}

\author{
ÁNGELA MADRID Y MEDINA \\ Instituto de Estudios Manchegos
}

\begin{abstract}
SUMARIO
1. Introducción.- 2. La hospitalidad en la Orden de Santiago.- 3. La hospitalidad en la Orden de San Juan: 3.1. El modelo de Oriente. 3.2. La Península Ibérica. 3.3. El hospital de Consuegra. 3.4. La cofradía de Consuegra. 3.5. El precepto de la Hospitalidad.
\end{abstract}

\section{INTRODUCCIÓN}

El fenómeno de la hospitalidad, si nos remitimos a los fundamentos ideológicos de las órdenes militares, tiene en todas ellas las mismas constantes espirituales. Y similares prácticas religiosas, como la oración de los enfermos, los motivos de los donantes (por la salvación de sus almas y las de sus familiares), la creación de capellanías.

Cambian las circunstancias que dan origen a la Orden Hospitalaria de San Juan de Jerusalén y a las Órdenes Militares españolas. Aunque, con el paso del tiempo y el fin de la Reconquista, los hospitales santiaguístas de frontera evolucionen desde la atención a heridos en combate y redención de cautivos, al cuidado de los pobres' ${ }^{1}$. Los del Camino de Santiago siempre se

\footnotetext{
'Sobre la hospitalidad en las Órdenes Militares españolas puede verse Ángela MADRID Y MEDINA, Las Órdenes Militares y la asistencia hospitalaria, "Lux Hispaniarum", en vías de publicación por el IEM y el Real Consejo de Ordenes de Caballería.

"Anuario de Estudios Medievales". 28 (1998)
} 
ocuparon de ellos, ya que los peregrinos lo eran en su mayoría, e, incluso, de leprosos ${ }^{2}$.

\section{LA HOSPITALIDAD EN LA ORDEN DE SANTIAGO}

Regina Sáinz de la Maza no pasó por alto la hospitalidad al estudiar la Orden de Santiago, que tiene en común con la de San Juan la Regla de San Agustín. Desde hace tiempo sabemos por ella que en Aragón ${ }^{3}$ contó con tres de las ocho Casas de la Merced que en los primeros tiempos se fundaron en la Península: la del hospital de san Bartolomé (desde 1228 Casa de la Merced) de Zaragoza, la de Teruel y la Casa de la Merced de Castiel en el obispado de Segorbe.

En el primer caso considera que, si no fue fundado por santo Domingo de Guzmán, al menos a él puede deberse su formación y reglamentación. Parece que, incluso, residiría en él durante el tiempo que pasaba en Zaragoza, y que regresaría de Italia para salvarlo de la decadencia. A mediados del XIII dejó de ejercer la redención de cautivos y sus bienes debieron pasar a la encomienda de Montalbán.

Un pleito de 1241 entre el comendador de san Marcos de Teruel y un diácono de la iglesia de san Andrés, acerca del pretendido derecho de ambos sobre unas casas contiguas a san Marcos, nos aporta alguna noticia sobre el hospital de Teruel. Los jueces dictaminan que el diácono ha de disfrutar de las casas y se le entregaba el hospital ${ }^{4}$, que pudo ser fundado por el rey Alfonso II en 1188, durante cuatro años. Finalizado este periodo pasaría a la encomienda de san $\operatorname{Marcos}^{5}$.

Los hospitales santiaguístas ${ }^{6}$ son fundados a fines del siglo XII en su mayoría, recién nacida la Orden. Su localización responde, en gran medida, a la extensión territorial de la misma.

\footnotetext{
${ }^{2}$ Vid. MADRID, La presencia de hospitales santiaguistas en el Camino de Santiago, "Homenaje al Prof. José Filgueira Valverde", Pontevedra, Museo, en prensa.

${ }^{3}$ Regina SÁInz de la MaZa LaSoli, La Orden de Santiago en la Corona de Aragón, Zaragoza, 1980, pp. 123 y ss.

${ }^{4} \mathrm{AHN}$, OO.MM, Carp. 324, no 4.

${ }^{5}$ SÁINZ DE LA MAZA, Op. cit., p. 127.

${ }^{6}$ Vid. MADRID, Las Órdenes.
} 
Con dos grupos' fundamentales: los hospitales del Camino de Santiago (Las Tiendas y Villamartín) y los hospitales de la frontera (Cuenca, Talavera, Toledo, Mora y otros).

Gozaron del favor de papas, reyes, magnates y diversos particulares, constituyendo algunos de estos hospitales importantes encomiendas. Recibieron considerables beneficios espirituales y donaciones económicas en servicio de Dios y para la salvación de las almas de los donantes.

Alejado el peligro musulmán experimentaron entonces un proceso de concentración. Algunos absorbidos por los de Toledo (rentas de Ávila y Talavera) y Cuenca (el de Alarcón). Otros llegaron a desaparecer. Los que se mantuvieron lo hicieron en nuevos edificios, de diferente tipología ya y proporciones mayores.

El hospital de Toledo subsistió hasta el siglo XIX. El de Cuenca, convertido hoy en residencia de ancianos, ha sobrevivido hasta nuestros días.

\section{LA HOSPITALIDAD EN LA ORDEN DE SAN JUAN}

En la obra póstuma de la Dra. Sáinz de la Maza encontramos referencias a otro hospital, en el monasterio sanjuanista de Sigena. Promovido por la reina Leonor en 1357, las obras terminan oficialmente en 1373. Estuvo destinado a pobres ${ }^{7}$.

\subsection{El modelo de Oriente}

La Orden Hospitalaria de San Juan de Jerusalén gira, a lo largo de toda su historia, en torno a la hospitalidad. Se ha afirmado ${ }^{8}$ que en 1160 el hospital de Jerusalén acogía a 2000 enfermos, a los que el Maestre Des Moulins había ordenado que se les proporcionara tres veces por semana carne fresca, personalizando la que era más conveniente para cada enfermo.

El Hospital de Rodas, una vez trasladada allí la sede de la Orden, se concluyó en 1478. Poseía una gran sala de 51 por 21 metros, a la que se

${ }^{7}$ SáINZ dE LA MAZA, El monasterio de Sijena, Barcelona, 1998, pp. 5 y 6.

${ }^{8}$ Vid. Antonio PaU Arriaga, La soberana Orden de Malta, Madrid, 1996, pp. 89 y 90. 
añadirían once cámaras más en la segunda planta para aislar a los enfermos que lo requiriesen. Contaba con farmacia y otras dependencias 9 .

En este hospital, según los Establecimientos de la Orden, "los dolientes de qualquier generación y nación Christiana son recibidos, curados y recreados y con despesas de nuestro tesoro nutridos y medicinados de sos enfermedades" ${ }^{\prime \prime}$.

\subsection{La Península Ibérica}

Los hospitales sanjuanistas se distribuyen por amplios territorios, siendo más tardíos los del Priorato de San Juan en La Mancha. Todavía en el siglo XVIII existe una preocupación por mantenerlos y renovarlos ${ }^{11}$.

Adrián Arcaz ha estudiado los de Galicia ${ }^{12}$. Del hospital de San Pedro Félix de Incio, en Lugo, también se ha ocupado José Manuel González Sánchez ${ }^{13}$.

En el Camino de Santiago levantaron también el de Villapañada, en Asturias y, en León, el de Órbigo ${ }^{14}$. En Benavente existió un hospital bajo la advocación de San Juan Bautista ${ }^{15}$.

En el siglo XII hemos encontrado dos referencias hospitalarias en Burgos. La alberguería de Atapuerca, fundada por Alfonso VII, para atender a los pobres ${ }^{16}$. De 1165 es la donación de Alfonso VIII de la villa de Barrio de San Pedro de Reinoso al hospital y puente que entre Reinoso y el Barrio de San Pedro edificó Gutierre Pérez de Reinoso ${ }^{17}$.

\footnotetext{
${ }^{9}$ Ibidem, p. 90.

${ }^{10}$ AHN, OO.MM., Libro 1525. Segunda Partida.

"Vid. MADRID, La Orden de San Juan de Jerusalén en La Mancha: su proyecto hospitalario, "Actas de las II Jornadas de la Orden de San Juan". Ciudad Real, IEM, en prensa.

${ }^{12}$ Adrián ARCAZ POzo, La hospitalidad sanjuanista en la Galicia medieval. Ibídem.

${ }^{13}$ José Manuel GONZÁLEZ SÁNCHEZ, Las Órdenes Militares y la labor asistencial en el Camino de Santiago: Hospital de San Pedro Félix de Incio. En: H. SANTIAGo OTERo (ed.), "El Camino de Santiago, la hospitalidad monástica y las peregrinaciones", Salamanca, 1992, pp. 241 y ss.

${ }^{14}$ VÁZQUeZ DE PARGa, LACARRA Y URÍA, Las peregrinaciones a Santiago de Compostela, II, Madrid, 1949, p. 306.

${ }^{15}$ Juan Ignacio MARTín BENITO et alii, Los caminos de Santiago y la iconografía jacobea en el norte de Zamora, Benavente, 1994.

${ }^{16}$ Carlos de Ayala Martínez (com), Libro de los Privilegios de la Orden de San Juan de Jertusalén en Castilla y León, Madrid, 1955, pp. 162 y 163.

${ }^{17}$ Ibídem, pp. 257 y 258.
} 
Otro intento, en 1159, es el caso del hospital de Villar de Fallaves $^{18}$. Posterior (de 1220) es la donación hecha por el rey Fernando III el Santo de la bodega de "Cevico" al hospital de Santa María, destinado a los pobres $^{19}$.

En el Archivo de la Asamblea Española de la Orden ${ }^{20}$, todavía en el Camino de Santiago, se menciona el hospital de Indurain (Navarra) y en Cantabria se cita el de Castro. Debe ser el de Santa María, ya existente en tiempos de Pedro I de Castilla ${ }^{21}$.

En la Corona de Aragón: Huesca (1204; en 1334 había una casa antigua y una casa nueva de hospital), Alguaire (en el siglo XII era prior Frey Guillermo de Rubio), Ares (fundado en 1164), Berbegal (s. XIII), Jerusalem de Vic (1228) y San Valentín de les Cabanyes ${ }^{22}$.

Portugal no es ajeno a la actividad sanjuanista. Como ejemplo el hospital de Braga, estudiado por José Marques ${ }^{23}$.

\subsection{El hospital de Consuegra}

Hemos de llegar a la baja Edad Media, 1453, para encontrarnos ya con una fundación hospitalaria importante en el Priorato de Castilla y León de la Orden de San Juan en La Mancha: el hospital de Consuegra, bajo la advocación de San Juan Bautista.

No es la única. En el territorio, a escasa distancia (dos leguas) encontramos un hospital en el Convento de Santa María del Monte. Guerrero Ventas recoge la bula del Maestre Jacobo Milly de 18 de noviembre de 1454 en que dispone que el "Hospital anejo este dotado de cualquier medio que pueda servir de alivio, gozo, recreación o remedio a los pobres y enfer$\operatorname{mos}^{124}$.

\footnotetext{
${ }^{18}$ Ibídem, pp. 244 y 245.

${ }^{19}$ Ibídem, pp. 417 y 418 .

${ }^{20}$ Archivo de la Asamblea Española de la Orden de Malta. Sin catalogar.

${ }^{21}$ Fernando BARREDA et alii, Rutas jacobeas por Cantabria. Santander, Centro de Estudios Montañeses, 1993, p. 178.

${ }^{22}$ Todo ello según los datos que constan en el archivo de la Asamblea Española de la Orden. 1989.

${ }^{23}$ José MARQUeS, A assistência no Norte de Portugal nos finais da Idade Media, Porto,

${ }^{24}$ Pedro Guerrero Ventas, El gran Priorato de San Juan en el Campo de la Mancha, Toledo, diputación, 1969, p. 149.
} 
La fundación del hospital manchego, para atender a los pobres, se debe a Gonzalo de Quiroga, entonces Gran Prior en Castilla y León, y a "todos los vesinos e moradores casados e vyudos de la su villa de Consuegra...por causa de la pestilencia". Es deseo del Prior que toda la villa se implique en el proyecto del mencionado hospital y de la cofradía, redactando unos estatutos por los que se debía regir la misma ${ }^{25}$.

En la Baja Edad Media fundan, así mismo, en Navarra dos hospitales: el de Bargota y el de Pamplona. Las primeras noticias sobre ellos son del siglo XIV. "Damos" - el Capítulo General a Sancho Ortiz de Azanza, un donado- "a uos aqueylla nuestra enffermería de la dicha casa de Bargota, en especial guarda et comienda... con tal condiçión que uos... mantengades et firmades et gouernedes los enffermos... et a las dos dueynnas que ayllí fincan"26. Es el 20 de agosto de 1307, siendo prior Guy de Severach. Imaginamos que las dueñas también habían entrado en la Orden, seguramente como donadas.

Juan del Bosco es comisionado por el Maestre, el 24 de febrero de 1440 en Rodas, para considerar con la reina Blanca de Navarra la conveniencia de constituir un hospital para pobres en su casa de Bargota ${ }^{27}$.

Se llegó a fundar la casa del Crucifijo de la Puente por Juan de Beuamont ${ }^{28}$, e incluso, mucho después, el 9 de octubre de 1534 se estableció una cofradía y hermandad del Santo Crucifijo ${ }^{29}$. Sin embargo, el propio Beaumont en el Capítulo General del 11 de mayo de 1469 había fusionado la casa de Bargota al Crucifijo ${ }^{30}$.

Por lo que se refiere al hospital de Consuegra, tenemos constancia de su existencia todavía en 1800 , fecha en la que el prior seguía ocupándose de su buen estado de conservación ${ }^{31}$.

\footnotetext{
${ }^{25}$ Archivo General de Palacio (en lo sucesivo AGP). Papeles del Infante don Gabriel. Anexo, leg. 1

${ }^{26}$ Santos García LARRAGUETA, El régimen de encomiendas en documentos sanjuanistas del siglo XIV, "I Simposio Histórico de la Orden de San Juan", Madrid, 1990. Inédito.

${ }^{27} \mathrm{AHN}$, OO.MM, Carp. 907, $\mathrm{n}^{\circ} 6$.

${ }^{28} \mathrm{AHN}$, OO.MM., Carp. 907, $\mathrm{n}^{\circ} 12$.

${ }^{29} \mathrm{AHN}$, OO.MM., Carp. 907, $\mathrm{n}^{\circ} 13$

${ }^{30}$ AHN, OO.MM., Carp. 907, no 12.

${ }^{31}$ AGP, Papeles. Leg. 159 (Cit. Huerta, Muela y Poveda, Herencia. Ciudad Real, BAM, 1991, p. 202)
} 


\subsection{La cofradía de Consuegra}

Las cofradías contribuían al buen funcionamiento del hospital. En los Establecimientos de la Orden de San Juan disponen, con respecto a los cofrades: "debaxo del título de confraternidad de las buenas obras de nuestra religión hazer partiçipantes las personas seglares" ${ }^{32}$.

El Papa Sixto IV autorizó a que en cada casa de la Orden se pueda establecer una hermandad. Como hemos visto hay una cofradía y hermandad del Santo Crucifijo, en Navarra. En las Ordenanzas del Santo Crucifijo, de 1534, aparece la concesión de indulgencias a los que visiten iglesias, oratorios u hospitales de la $\operatorname{Orden}^{33}$.

Para contribuir, pues, al sostenimiento de estos hospitales, lo que no siempre era tarea fácil, es por lo que surge la cofradía en Consuegra, cabecera del Priorato.

La fundación del hospital, el 29 (el mal estado de conservación del legajo ${ }^{34}$, roto en algunas partes, impide leer el mes, así como una serie de detalles) de 1453, viene acompañada de una cofradía. En ella se estipulan aspectos que afectan no sólo al funcionamiento interno de la misma, sino también al del hospital.

El Prior Gonzalo de Quiroga se comprometía a contribuir con 1000 maravedíes, 20 fanegas de trigo y una dotación anual. Cada uno de los cofrades debía ingresar 10 maravedíes. Era obligación de los cofrades ocuparse del ciudado de las casas, viñas y heredades.

Todos los cargos de la cofradía estaban obligados a prestar servicios en el hospital. Consistían esos en un prioste, dos alcaldes, un portero y oficiales (que deben atender a los pobres). A los seis criados que habrá permanentemente han de pagarles un mínimo de cinco libras.

Los cofrades, a quienes se dictan una serie de obligaciones religiosas, están obligados a celebrar cabildo tres veces al año. Aprovechando para inspeccionar el hospital y ordenar los reparos necesarios al mismo.

\footnotetext{
${ }^{32}$ AHN, OO.MM., Libro 1525, fol. XVI v.

${ }^{33}$ AHN, OO.MM., Carp. 907, no 13.

${ }^{34}$ AGP, Papeles, Anexo, legajo 1.
} 
El mantenimiento y la limpieza del hospital queda al cargo de un hospitalero, nombrado al efecto, con su muger uelada ${ }^{35}$. Por los servicios prestados se le exime del pago de impuestos.

Permanentemente tiene que haber en el hospital un mínimo de ocho camas, destinadas a los pobres, sobre un soporte de madera, con un almadraque, un par de sábanas y dos mantas.

La cofradía se hace cargo de los gastos de enterramiento de los pobres. Se establece una regulación sobre ello, con misas y oraciones.

El incumplimiento de las normas lleva aparejado un sistema punitivo, siendo los alcaldes los encargados de ejercer la justicia. No debe los cofrades causar ningún daño. La escribanía o cualquier otro oficio ha de ser desempeñado debidamente. Se prohibe injuriar a otro cofrade. No cuidar del bien del cabildo se penaliza con multa de diez maravedíes. Y con veinte si no se quiere tomar el lecho del difunto.

En la cofradía existe un sistema de sucesión. El primogénito del cofrade o cofrada fallecidos, puede entrar en aquella pagando diez maravedíes. Los siguientes hijos también tienen la posibilidad de hacerlo. Si no se opone la mayoría del cabildo.

Cuando el cabildo decide labrar las tierras de cereales y viñedo de la cofradía, cada cofrade ha de enviar, cuando se lo mande el prioste o el alcalde, la mejor yunta de bestias o de bueyes con su onbre e todo su aparejo $^{36}$. En caso de no poseer animales, debe acudir de todas formas, personalmente o enviando a otro en su lugar.

Por último, al cofrade o cofrada al que se muriese el animal de labranza se le da un plazo de un año para comprar otra. Y, en cualquier caso, están obligados, bajo juramento, a aumentar en la medida de lo posible el provecho y honor de la citada cofradía.

\subsection{El precepto de la hospitalidad}

En la fundación del hospital, se explica que el Prior "e todos los vesinos e moradores casados e vyudos de la su villa de Consuegra promovidos a caridad e doliéndonos de los pobres...nuestros hermanos, para ellos e

\footnotetext{
${ }^{35}$ Ibidem.

${ }^{36}$ Ibídem.
} 
para su acogimiento e recreación fecimos a nuestras comunes espensas el hospital".

Desde la bula Piae Postulatio voluntatis del papa Pascual II, 15 de febrero de 1113, considerada el documento fundacional de la Orden Hospitalaria de San Juan de Jerusalén, en que ya se menciona la atención a pobres y peregrinos ${ }^{37}$, a toda una serie de publicaciones de diferentes épocas, recogiendo los estatutos de la orden, nos hablan de las obligaciones hospitalarias de la misma.

La documentación del Archivo Histórico Nacional guarda algunos de estos Estatutos ${ }^{38}$. En la Regla, Raimundo de Podio se declara "seruidor de los pobres de Hiesucristo y del Hospital de Herusalem"39 y, junto a los tres votos de pobreza, castidad y obediencia, deja claro el programa hospitalario ${ }^{40}$. Los caballeros de San Juan se comprometían a "ser siervo y esclavo de nuestros señores los enfermos"41.

La atención a los más degradados transciende incluso la enfermedad. El malogrado príncipe de Viana concede el 28 de marzo de 1452 a Juan de Beaomont y al hospital de la Orden en Pamplona que todos los cristianos que sean ejecutados en el patíbulo en esa ciudad puedan ser enterrados en la iglesia del hospital de la Orden ${ }^{42}$.

El maestre Juan de Lestich establece diferentes remedios para los enfermos de los hospitales de la Orden. Naturalmente hay que contar con las oraciones, pero no hay que despreciar la ciencia, ya que "Dios sapientísimo y clementísimo no queriendo fallescer al spiritual y corporal prouecho de la

\footnotetext{
${ }^{37}$ Carlos Morenés y MARiÁtegui, Historia resumida de la Soberana Orden de Malta, Madrid, ICOMAL, 1995, p. 15

${ }^{38} \mathrm{AHN}$, OO.MM., Libros $1550 \mathrm{C}, 1525,508$ y 1355 C.

${ }^{39}$ Ibidem. Libro $1525, \mathrm{VII}^{\circ}$

40" Del exercicio de la Milicia de Christo a la Orden nuestra del tiempo de su primera institución, por sufragios y magnificencia de la sancta fede apostólica, príncipes y deuotos christianos an dotado y aumentado, anpliado y enriquescido de priuilegios, gratias y juridiciones y canpos y posesiones porque los caualleros de aquella profesos i flamados de uerdadera caridad, madre de las virtudes, con firme fondamento deuan aiuntar y copular la miliçia y fortaleza de la fe a la sancta Hospitalidad y usando de doble exerçiçio entendian hazer virtuosas cosas y propia verdaderamente a los caualleros de Christo..." Ibídem, fol. VIII v.

$Y$ añade: "no teman entrar en los peligros por el nonbre de Christo, Saluador nuestro, por el verdadero señal de la Cruz, por lá libertad de la Yglesia, por la Justiçia, por los pupilos, por las biudas..." Ibídem, fol. VIIII.

${ }^{41} \mathrm{PAU}$, op. cit., p. 89.

$42 "$...patibulo capitis pena demun quorus mortes suplicio ...cadauer et cadauera propia ...supultem(um) eclesiastice tradendi in dicto hospitali". AHN, OO.MM., Legajo 8488, $\mathrm{n}^{\circ} 18$.
} 
umana naturaleza permitió la expertísima y utilísima arte de la medicina...porque no devemos tentar a Dios, mas adiudarnos con los médicos, los cuales por su saber mandan que sean onrados. Y por esto, por utilidad de los dolientes de la enfermería, sean deputados médicos honrados de ciencia y plática, honbres honestos y modestos y experimentados.

Y los dichos médicos devan visitar los dolientes a lo menos dos vezes al día y con solicitud y prudençia hordenar todas las cosas que a la salud de los dolientes conuiene" ${ }^{43}$. La visita han de realizarla en compañía del enfermero y el escribano.

Tienen los médicos, así mismo, que visitar la botica, para que no existan fallos por culpa del especiero. El cirujano ha de ser, igualmente, de probada fe y experimentada ciencia ${ }^{44}$.

Los prodomos inspeccionarán diariamente la despensa. "Y porque los inttrimentos del cuerpo humano quanto más son puros y mejores tanto más han en prouechosos comeres como es pan, vino, pollos y gallinas; de lo qual el enfermero de las dichas cosas haga provisión"45.

La alimentación ${ }^{46}$ adecuada es, sin duda, un remedio saludable. En los hospitales de la Orden de Santiago tampoco se les escapa este aspecto. "E ponemos para los poures del hospital de Uillamartín que ayan los ...que albergaren dos dos (sic) panes e los que passaren de día senos panes, e ponemos ...que ayan sennas fiaras de uino y los que passaren de día otras sennas fiaras de uino. E ponemos que ayan carne los poures que albergaren III días en la semana, e quantos poures pasaren de día e quantos a la noche albergaren que ayan so ración de conducho. E este conducho pueden auer de sos huertos, e queso e queso (sic) e manteca ayan de sos oueias lo que les Dios dier"47.

Y todavía en 1769 Aguirre, al hablar del hospital de Santa María del Monte, refiriéndose a la gran cantidad de pobres, que acuden diariamente,

\footnotetext{
${ }^{43}$ AHN, OO.MM., Libro 1525. Segunda Partida.

${ }^{44}$ Ibidem.

${ }^{45}$ Ibidem.

${ }^{46}$ No podemos detenernos aquí en temas de alimentación. Puede verse, por ejemplo, La vida cotidiana en la Edad Media, "VIII a Semana de Estudios Medievales de Nájera", Logroño, IER, 1998. Aparte de algunos artículos, incorpora una bibliografía sobre este asunto.

${ }^{47}$ MADRID. La presencia.
} 
incluso del extranjero, a este hospital, afirma que a todos ellos se les sirve dos comidas decentes ${ }^{48}$.

En definitiva, un programa de actuación hospitalaria que, incluso hoy, en muchos aspectos (dedicación sanitaria, alimentación como medicina preventiva, preocupación por los grupos sociales más degradados) nos parece muy actual.

\section{RÉSUMÉ}

L'hospitalité c'était une des activités les plus importantes des Ordres Militaires, spécialement, en ce qui concerne l'Ordre de Saint Jean, parce-que constituait sa propre activité. L'Ordre de Santiago avait des similitudes avec l'Ordre de Saint Jean en cet aspecte.

Cet article analise divers hôpitaux de toute l'Espagne. On explique l'importance de la maintenance des cofradies, les bases ideologiques qu'inspiraient l'hospitalité, et on étudie aussi l'attention prêtée aux pauvres malades.

\section{SUMMARY}

One of the most important activities of the Military Orders was the hospitality. In the case of the Saint John's Order, the hospitality is his peculiar activity. The Santiago Order acted like Saint John's Order in this aspect.

In this article, the authoress studies some Hospitals, all over Spain, and the importance that brotherhoods had in the sustenance of hospitality. It is mentionned also the ideology that ispired that hospitality. The care offered to the sick people is analyzed too.

${ }^{48}$ Domingo AguiRre, El Gran Priorato de San Juan de Jerusalen en Consuegra en 1769 , Toledo, 1973, p. 87. 